\title{
Understanding the needs of individuals at risk of perpetrating child sexual abuse: A practitioner perspective
}

\author{
Sara Goodier and Rebecca Lievesley
}

\begin{abstract}
Research estimates that as many as one in twenty children in the UK have been a victim of child sexual abuse. The scale of this problem motivates prevention efforts, however there is an apparent absence of preventative intervention for those individuals who are concerned about their sexual preference for children, including those who have not committed an offence. Due to the sensitive nature of child sexual abuse and stigma surrounding paedophilia, individuals who are concerned about their sexual interests in children are unlikely to willingly participate in research. By investigating the experiences of staff that are employed by an organisation offering an anonymous helpline for people who experience sexual thoughts and behaviours towards children, this research aims to develop understanding of the needs of those individuals, in order to establish how child sexual abuse might be prevented. Semi-structured interviews were conducted with five practitioners from a sexual abuse prevention organisation and thematic analysis revealed three main themes; Moving service users forward, Barriers to intervention and Prevention: Missing pieces. The first theme identifies ways in which practitioners may help service users to identify their problem, associated risk factors and how they might begin to move forward. The second theme addresses certain factors that prevent service users from accessing or engaging with primary interventions. Finally, the third theme discusses the ways in which primary prevention could be built upon, by considering participants experiences that are shaped by their work in the field of primary intervention, and their experience of service users. This is the first time the needs of those who may benefit from primary prevention in the UK have been explored in this way; therefore each theme is discussed in relation to primary prevention of child sexual abuse.
\end{abstract}




\section{Introduction}

Child sexual abuse (CSA) is defined as forcing or persuading a child to take part in sexual activity (nspcc.org, 2016a). It is not limited to physical contact including behaviours such as grooming, exploitation and illegal online activities involving indecent images of children (nspcc.org, 2016a). In terms of child safety across the world, CSA and the viewing of sexual images containing children are major problems. In the UK, over 36,000 sexual offences against children were recorded last year (nspcc.org, 2016a) and research estimates that one in 20 children (Radford et al., 2011) have been sexually abused, increasing to as many as one in five across Europe (Council of Europe, 2010). However, it is established that such estimates are not fully representative of CSA prevalence (Horn et al., 2015) as many cases go undisclosed to the authorities. In fact, a survey of adults who experienced contact sexual abuse in childhood reported that $34 \%$ of cases were undisclosed at the time (Radford el al., 2011). Similarly, in a sample of women sexually abused as children, as many as half disclosed that nobody else knew they were victims (Horn et al., 2015).

It is clear that large numbers of children are becoming victims of sexual abuse and the threat continues as technology develops, creating opportunities for those with sexual interests in children to commit offences via the internet (National Crime Agency, 2013). For example making, viewing or distributing child abuse images (Jutte, Bentley, Miller \& Jetha, 2014). This is reflected in figures from an online CSA prevention charity that retains the authority to remove sexual content involving children from the internet. Their figures show a $417 \%$ increase in reports of indecent images and videos of children since 2013; an increase of 188\% over the previous year (Internet Watch Foundation, 2015).

The scale of this problem motivates prevention efforts; however attempts by the criminal justice system (CJS) to address CSA tend to be executed following the disclosure or detection of a sexual offence (Brown \& Saied-Tessier, 2015). Interventions for those who have committed sexual offences such as incarceration, sex offender treatment programmes and the sex offender registry, are known as tertiary prevention (McMahon, 2000) which aims and may contribute to reduction in recidivism rates. However, these examples are limited to individuals who are known to the authorities and involved in the CJS. Alternatively, primary and secondary prevention efforts occur mainly within the community targeting whole populations and groups deemed to be at higher risk of becoming a victim or perpetrator of CSA (Piche et al, 2016). Estimates report that as many as 5\% of men find children sexually attractive (Seto, 2008), 
therefore the apparent gap between estimates of those who are sexually attracted to children (Seto, 2008) and actual offending rates strengthens the argument for efforts to prevent child sexual offences before they occur. The combination of primary, secondary and tertiary levels of prevention exemplify a public health approach which aims to monitor the scope of CSA incidents while engaging in research to develop prevention strategies (Whitaker, Lutzker \& Shelley 2005). Efforts of primary and secondary level prevention have increased in recent years and, although much less developed than post-offence prevention such as rehabilitation and treatment programmes, demonstrate opportunity to reduce CSA (Horn, 2015). The aim is to prevent victims by targeting those who are at risk of victimisation or prevent potential abusers from committing offences (Smallbone, Marshall \& Wortley, 2008)

Recognition that tackling CSA requires multiple levels of prevention has resulted in some education focussed efforts. School-based CSA prevention programmes have shown effectiveness in increasing children's skills in protective behaviours, and may reduce a child's risk of being sexually abused by as much as half (Gibson \& Leienberg, 2000). In addition to educating children, recent media campaigns attempting to increase parental knowledge about how to discuss sexual abuse with children in an age-appropriate way received positive feedback, and even resulted in reports of abuse disclosures following the implementation of advice (Brown \& Saied-Tessier, 2015).

Internationally, other media campaigns have successfully reached potential abusers who may be at risk of committing offences (Beier et al., 2009). For example, the German Prevention Project Dunkelfeld (PPD) launched in 2005 (Beier et al., 2015) with the initiation of a media campaign to encourage self-identified (and undetected) individuals with sexual interests in children to seek professional help (Beier et al., 2015). The pilot investigation established that media campaigns which are empathic, non-judgemental and assure anonymity are most likely to get a response from self-identified paedophiles, particularly if the respondent is highly distressed (Feelgood et al., 2002). The first investigation reported a number of responses, indicating the utility of media in encouraging individuals with deviant sexual preferences to enrol in assessment and treatment, and outlines a novel preventative approach to reducing CSA. The PPD is an interesting example because the absence of mandatory reporting laws in Berlin allows the project to include individuals who had admitted to child sexual abuse or offences involving indecent images of children, but were not detected by the authorities. Therapists who report committed CSA or offences concerning indecent images of children to the authorities are considered to be in breach of confidentiality by German legislation (Beier et al., 2015). 
This opens the door to treatment for undetected offenders without involving the CJS, encouraging individuals to come forward for help.

In contrast, legal obligations to report cases of child abuse in the UK are in place for all professionals, as are expectations from professional bodies such as the British Psychological Society (BPS) (BPS, 2009). Therefore, in this country individuals cannot come forward for help with sexual abusing behaviour without being reported to the police (Henry, 2001). This limits the possibility of developing prevention efforts comparable to the PPD. However, for those who have sexual interest in children but have not committed any offences UK law is comparable to that in Berlin, allowing for organisations that offer advice and support via services such as helplines. On evaluation, the observed usage of such services highlights the possible utility of primary and secondary prevention projects in the UK in protecting children from CSA. This is reinforced by research investigating the experiences of sexual offenders convicted for sexual abuse. Research suggests that many incarcerated sex offenders would have accessed a preventative service had it existed prior to their offence, where free counselling and group treatment are perceived as potentially useful pre-offending treatments (Piche et al., 2016). Although the sample cited here was Canadian it is likely that a disposition for prevention services is applicable more widely, particularly as a time frame of almost a decade between onset of sexual fantasies and the time of the first arrest is estimated (Piche et al., 2016).

Based on the above, there is an apparent absence of preventative intervention for those individuals who are concerned about their sexual preference for children, but have not committed an offence, or those offending but undetected by the authorities. Therefore, it is fundamental to understand the needs of those who may potentially engage in sexual offending behaviour in order to establish how it might be prevented. Unfortunately, due to the sensitive nature of CSA and stigma surrounding paedophilia (Jahnke \& Hoyer, 2013) individuals who are concerned about their sexual interests in children are unlikely to willingly come forward and participate in research. Alternatively, it is highly likely that the staff working for prevention programmes, who interact with members of this target group on a daily basis will have substantial insight into their needs and greater understanding of the issues they face, yet at present no study has attempted to utilise this population. As such, this investigation focuses on experiences of staff who are employed by an organisation that offers confidential support and advice via an anonymous helpline for people who experience sexual thoughts and behaviours towards children; a novel research area in the UK. The aims and purpose of the current research are to gain knowledge and understanding of individuals at risk of perpetrating CSA, and to gain 
insight into their needs and to gain expert perspectives on how to prevent CSA from occurring from the practitioners who work with individuals at risk of committing offences. Gaining knowledge in these areas hopes to successfully inform future prevention strategies.

\section{Method}

\section{Context}

In order to maintain anonymity of the staff members involved in this study, and in turn the privacy of the callers with whom they have worked with, the name of the organisation will not be identified and therefore will only be referred to as Organisation 1. Organisation 1 is an organisation that aims to prevent CSA by supporting adults, families and communities. This includes engaging with individuals who have concerning sexual thoughts and behaviours in order to promote protective action and encourage people to speak out. The organisation utilises various mediums such as media campaigns, a self-help website, an anonymous email service and an anonymous telephone service (helpline).

The helpline's first-line operators are shift workers with an array of backgrounds; they are required to have an empathic nature and good communication skills, and assist callers with their worries by helping them identify the seriousness of their concerns, offering support and providing information. All first line operators receive the same training, regardless of background, involving two days of workshops during which they gain knowledge about the helpline, the different types of calls, and appropriate ways to respond to differing needs. The operator's role is to gain information about the situation, ascertain whether anyone is at risk, and advise on further action. If deemed appropriate for the service user (SU), they are referred for a follow up with an experienced practitioner who calls them back at a suitable time to explore their presenting concerns in more detail. All practitioners have a high level of experience with sexual offending which allows them to focus on problematic behaviours in detail, and provide individually tailored, therapeutic support and advice regarding how to manage different situations. It is with these practitioners that the current research was conducted.

\section{Participants}


Participants $(n=5)$ were recruited via email, where all staff members who had experience with practitioner call back sessions were invited to participate. Out of the 11 eligible individuals, 5 volunteered to participate (see Table 1 for additional participant information).

Table 1: Participant information

\begin{tabular}{lll}
\hline Participant number & Role & $\begin{array}{l}\text { Time at the } \\
\text { organisation }\end{array}$ \\
\hline Participant 1 & Practitioner and Forensic Psychologist & 11 years \\
Participant 2 & Practitioner and Assistant Psychologist & 4 years \\
Participant 3 & Practitioner and Clinical Manager & 9 years \\
Participant 4 & Practitioner & 8 years \\
Participant 5 & Practitioner & 4 years \\
\hline
\end{tabular}

\section{Procedure}

Ethical approval was gained from a UK University in accordance with the BPS code of conduct (BPS, 2009). Data were collected through semi-structured interviews which lasted an average of 52 minutes (Range: 42-62 minutes). The semi-structured interview schedule was developed prior to data collection and consisted of open questions to provide a framework for each interview while facilitating discussion. The interview schedule addressed four broad areas; practitioner's role, practitioner views on current services, future prevention and understanding SU behaviour. Information sheets and the opportunity to ask questions were provided to participants. All participants signed a consent form and were debriefed post-interview. All interviews were conducted by the researcher, recorded onto a dictaphone and subsequently transcribed verbatim ready for analysis. To retain anonymity, all identifiable information was removed and participants were assigned a participant number.

\section{Analysis}

The choice of qualitative methodology was driven by these research aims in that thematic analysis aims to produce the identification of themes across the data set and thus capture important patterns of meaning in relation to the research question (Braun \& Clarke, 2006). 
Since thematic analysis acknowledges that individuals give their experiences meanings, and these meanings are influenced by the broader social context, it is considered to be 'reflecting reality' (Braun \& Clarke, 2006) and therefore offers the most appropriate method of capturing meaningful themes from participant narratives. Additionally, due to current gaps in literature surrounding the research topic, thematic analysis was deemed the best fitting research paradigm as the apparent flexibility of the method, which is not tied to a specific theoretical framework (Braun \& Clarke, 2006), provides scope for further investigation and allows for the process of ‘identifying, analysing and reporting patterns’ across data (Braun \& Clarke, 2006).

The researcher loosely adopted techniques outlined by Braun and Clarke (2006) beginning by actively reading and re-reading the interview transcripts in order to become immersed in the data. During this familiarisation, an initial list of interesting aspects across the data was noted, followed by the generation of repeated patterns coded manually by writing notes on the texts. This resulted in a list consisting of different codes identified across the data set which were sorted and combined at a broader level (Braun \& Clarke, 2006) into themes. The consideration of relationships between themes allowed them to be divided and regrouped under three overarching, superordinate themes. Finally, inter-rater reliability was undertaken with the analysis being checked for credibility by the co-author to assess the validity of the interpretations (Willig, 2008) - analysis was undertaken by the first author, with the co-author analysing sections of the data in order to compare interpretations and provide credibility checks. Similar interpretations and themes were identified.

\section{Results and Discussion}

Following the thematic analysis, three main themes were identified from the dataset; Moving service users (SU's) forward, Barriers to intervention and Prevention: missing pieces. Table 2 depicts the delineation of each theme, which are discussed in depth.

Table 2: Superordinate and subordinate themes

\begin{tabular}{ll}
\hline Superordinate Themes & Subordinate Themes \\
\hline 1. Moving SU's forward & 1.1. A person-centred problem \\
& 1.2. Capacity to engage
\end{tabular}


1.3. Working with risk factors

2. Barriers to intervention

3. Prevention: missing pieces
2.1. SU's lack of trust in services

2.2. Anonymity- undetected SU's

3.1. Publicity and funding

3.2. Lack of (adequate) services

3.3. Education

\section{Superordinate Theme 1: Moving SU's Forward}

Participants discussed considerations necessary to help service users (SU's) move forward, including; the presenting problem, how practitioners might help by identifying and addressing risk factors, and factors affecting SU engagement with such help.

\section{Subordinate theme 1.1: A person-centred problem}

An important aspect of investigating and understanding the needs of those who may potentially engage in offending behaviour is identifying the presenting problem; that is why might SU's initially call the helpline? Participants discussed how in recent years calls have shifted from a large proportion of incoming calls from internet offenders in the CJS, to a variety of different individuals calling at various 'phases in their journey' (Participant 5). Primarily, the main reason cited by participants for SU's calling the helpline is a level of 'concern'. This includes callers concern about their own thoughts, feelings or behaviours in relation to sexual interest in children, or concern about an individual they know, for example a family member displaying concerning sexualised behaviours such as 'sexting' a child (Participant 4). Essentially high levels of concern about someone's (not necessarily the callers) sexual interest in children is a prevalent the reason for calling the helpline.

Sometimes there are calls where people have called up and they're very clear that they're really, they suddenly notice that they're very troubled by their sexual thoughts that they've had about a particular child for example, and they want to talk to someone about that to try and understand it... there's always a level of distress. (Participant 3)

So you get people that can manage these things for a long long time and then sometimes there's an event or situation that might trigger er that... [it] undermines it and shakes up those strategies an makes them feel less robust... once upon a time they wouldn't have had contact with a child or they wouldn't be in a situation that has much proximity to 
children, that may change then that may increase the risk of the person maybe acting on this, or it's because you know they're in the environment they're exposed to those sorts of situations. (Participant 4)

Participant anecdotes such as this describe how SU's are essentially motivated to call by some internal discomfort, that is; they have suddenly become aware of the severity of their thoughts, they've acted on them or thought more about acting on them, the worry of getting caught becomes overwhelming or their situation has changed providing opportunity for offending behaviour.

Additionally, in terms of the presenting problem, practitioners are to some degree guided by the client. The service is voluntary therefore the only information staff members have about SU's comes from the SU's themselves. This means practitioners can only address problems presented to them by the client, thus, staff and SU's are generally in agreement about issues to be addressed and the path intervention might take. Challenges with this approach arise when individuals show minimisation or denial, however practitioners have the opportunity to address this; unlike in the CJS where denial is a barrier to treatment (Blagden, Winder, Gregson \& Thorne, 2013). Despite this, participants express how some discrepancy may arise when discussing what SU's want to get out of the service; 'some people think they will do our programme and then they're all fixed' (Participant 2). There can be a difference between practitioners and SU's expectations of how the service can help them and in some cases SU's have very high expectations, stemming from a desperation to be 'normal' (Participant 1).

\section{Subordinate theme 1.2: Capacity to engage}

In order for SU's to move forward with receiving intervention, capacity and willingness to engage with services are described by participants as necessary. Reducing initial stage anxiety and minimisation are expressed as important factors for ensuring this:

I think [the calls are] more about sort of managing their anxiety more than anything initially, and it's quite hard to get information from them in the first call and get them to take all of your advice on board in the first call because they're a bit sort of all over the place, but actually you'll find that if they call again and again and again they settle down a bit and they do start acting on things and you can kind of see an improvement. (Participant 2) 
Reducing the initial anxiety described here is important for various reasons. First, resources are limited and therefore it is in the best interest of practitioners from a prevention perspective to ensure intervention is only given to those who are 'ready, willing and able' (Participant 5) in order to contribute to the reduction of CSA. In addition, as services 'come at a premium' (Participant 3) practitioners have an ethical responsibility to make sure SU's are at an appropriate stage of emotional stability in order to deal with intervention. Finally, research concerning convicted sex offenders suggests engagement is correlated with treatment progress in group therapy (Levenson \& Macgowan, 2004), therefore those who are emotionally stable and able to more actively contribute, and are invested in the treatment are likely to progress further than those who are not. In terms of Organisation 1, crisis management is put in place to manage anxious callers. First-line operators hold on to SU calls until they feel progression to practitioner call-backs is appropriate for that individual.

As is to be expected, research (Levenson \& Macgowan, 2004) also reports that denial is inversely related to treatment progress, which is particularly important in relation to participants' experience of minimisation and denial from SU's:

They kind of come up with all these cognitive distortions trying to convince themselves that their behaviour's OK, so they might say 'well the child's already had a boyfriend or a girlfriend' or they might say 'well they're entitled to have their needs met' and 'the needs of the child aren't important' or they might tell themselves that the child enjoys it, erm or they might say that you know they didn't tell anyone so it couldn't have been that bad...you know they're gonner come up with all these excuses but mostly they have some awareness that they are just excuses. (Participant 5)

I say to them well why do you want to do [group work] if you don't feel like you've done it? Because I'm assuming then you think that you've got nothing to work on... sometimes they just haven't admitted it fully to us yet because maybe they're in a bit of a state of shock, so with them I won't put them through for a call back at this stage I would encourage them to look at the resources. (Participant 2)

This denial noticed by participants would, for convicted sex offenders, be a barrier to treatment as deniers are excluded from treatment programmes (Blagden et al., 2013). However, in the community denial may open up discussion with voluntary services as SU's have on some level admitted that their thoughts, feelings or behaviours require intervention by phoning the helpline. Organisation 1 encourage those who have 'not admitted things fully' (Participant 2) and are engaging in minimisation to use self-help resources available to the general public such 
as "The Porn Trap" (Maltz \& Maltz, 2009) as a strategy for eliciting deeper discussion and helping SU's to become aware of their own issues. This supports the argument for primary prevention because, unlike within the CJS (Blagden et al., 2013), even those not ready to confront deviant feelings or behaviours can be worked with.

Capacity to engage also refers to other issues such as mental health or substance abuse problems, and therefore promotes cooperation of services in dealing with problems that may inhibit SU ability to invest in intervention. Lack of such cohesiveness between services is considered by theme 3 .

\section{Subordinate theme 1.3: Working with risk factors}

From interview questions relating to risk factors, participant feedback highlights specific aspects they feel may contribute to offending pathways of SU's.

I think one of the risk factors which may seem quite obvious but comes through quite a lot on the helpline is having contact with children and having that opportunity to have unsupervised contact with children... the ones that don't have any contact with children erm feel quite protected I think because of that you know 'I don't have any contact with children', 'I don't have any unsupervised contact with children', 'there are no children in the family', 'I don't work with children', you know so that can actually help them in managing things, because being around children and having that opportunity is not a trigger that's there for them. (Participant 1)

Such accounts demonstrate opportunity as a risk factor within participant narratives, and highlight how a change in circumstance that is often out of the SU's control can increase likelihood of engaging in risky behaviours such as 'victim access behaviours' (Participant 5). Efforts to decrease opportunities for sex offences against children are apparent in types of legislation surrounding convicted sexual offenders in the community. For example, certain jurisdictions in the US restrict sexual offenders in the community from living certain distances away from child populated areas (Tewksbury \& Mustaine, 2006). In the UK the law is less extreme, however those with convictions are unable to work with children, and the Sex Offender Disclosure Scheme (Sarah's Law) allows police to disclose whether someone with access to a child has a record of CSA (nspcc,org, 2016b). Therefore, although opportunity may seem an obvious risk factor, it is identified in participant accounts as a key aspect of SU's perception of themselves as low risk. SU's may feel a sense of security in a position where 
(unsupervised) contact with children is unlikely. Absolute certainty that an individual with sexual interest in children is never going to offend may be discouraged by Organisation 1 staff:

[We] try and encourage people to step a bit away from the 'no it's never going to happen again', you know to actually thinking well 'what harm is it going to do if I do things to try and make sure of that'. (Participant 1)

A person's environment is volatile to change therefore ensuring that SU's in the community are aware 'protective' circumstances may not last, and preparing them to deal with changes regarding contact with children is an important consideration. Opportunity for sexual offending (particularly interfamilial molestation) is likely to peak in mid-adulthood when individuals are most likely to have their own children, or associate with friends or family who have children (Hanson, 2002). Practitioners (or indeed any professional working with this type of population) have a moral responsibility to ensure child protection. If an individual has not yet offended or indeed has not been detected and remains anonymous, the helpline staff rely on a certain level of trust, co-operation and responsibility from SU's to take action on advice that promotes child safety.

Additionally, isolation and lack of support are also discussed by participants as an aspect of increasing risk.

There are issues around isolation and support networks, so if people don't have anybody kind of in their lives that they can spend time with that they care about, that care about them you know family friends that kind of thing um I think that can be quite a risk...so even if there's somebody who had concerning thoughts but they have lots of friends and they spend their time kind of going out and doing social things an keeping busy erm that, that becomes better and easier for them than perhaps somebody who doesn't have that ability to go out and see people. (Participant 1)

A lot of them say to me that they try and stop doing what they're doing by themselves and most of them fail at that because they haven't got the people around them to egg them on and sort of support them, and also if they do fail they've got no one to 'fess up to because no one knows, they're only letting themselves down and actually that can make them feel worse over time and more inclined to kind of [offend]. (Participant 2)

Here, participants highlight how such loneliness and lack of support not only poses risk of increasing recidivism but adds to the difficulty of stopping offending behaviour by giving individual's time and space to engage in it. The negative effects of isolation in terms of 
offending are highlighted in the literature, for example never being married is associated with increased recidivism in sex offenders (Hanson, Steffy \& Gauthier, 1993). Evaluations of the previously discussed housing restrictions have shown unintended adverse effects such as feelings of isolation and loss of relationships (Levenson \& Cotter, 2005) and could increase sex offenders risk for recidivism (Bonnar-Kid, 2010), therefore strengthening the argument for primary prevention efforts.

In order for Organisation 1's service to be effective the practitioner's role is in some way orientated to addressing risk factors for each SU in an individualised way. In doing so practitioners discussed a focus on promoting positivity, both in the form of self-help and support from the service. Promoting a positive lifestyle and addressing issues surrounding selfesteem are valuable strategies coming through participant narratives:

I think we are very good at trying to help people separate things a little bit and think about this is just one part of you, you know this isn't all that you are and there are lots of other things about you that are really positive and you should feel good about. (Participant 1)

If you can help someone create a life they don't want to lose you can help bring the risk down does that make sense? So often we're talking to people about again it's back to the good lives model so it's about being physically and emotionally well, it's about being free from difficult thoughts and feelings, it's about being connected to other people, erm it's about having a sense of belonging you know so encouraging people to you know be part of adult based activities to do thing that they love and care about. (Participant 5)

For those in contact with the CJS, the Circles of Support and Accountability (CoSA) model is available to assist in the successful reintegration of individuals with deviant sexual interests back into the community, by providing prosocial sources of support (Duwe, 2013). Outcome evaluation studies of CoSA find significant reductions in sexual, violent and general recidivism of sexual offenders subsequent to involvement in Circles (Wilson, Cortoni \& McWhinnie, 2009). The focus on prosocial support and offender accountability is argued to help reduce feelings of isolation and loneliness while advocating a 'self-determined' lifestyle (Wilson et al, 2009). Such findings support work focussing on and developing SU strengths:

We will try and kind of press the importance of ... what kind of things you can put in place to think about, perhaps what areas of your life might you want to improve so kind of good lives sort of focus really. (Participant 1) 
It's very much 'I'm either a good person or I'm a really bad person for doing this' and they forget you now that there's more to them... the get help website is stuff about working on like self-esteem and helping people to think about what other sort of positive things are there in their lives and self-esteem is a really important thing. (Participant 1)

Here participants emphasise self-esteem. Indeed, the linear relationship between self-esteem and recidivism is demonstrated in the literature where low levels of self-esteem are related to increases in reoffending (Thornton, Beech \& Marshall, 2004). Low self-esteem may contribute to instances of resistance to positivity promoted by Organisation 1, an obstacle coming through participant narratives, where SU's struggle to accept positive aspects of themselves.

They're kind of wanting to be punished or feeling like they shouldn't do anything positive in their life because they've done this horrible thing. (Participant 5)

Increasing self-esteem and looking at the bigger picture helps to break this down and move SU's forward by showing them that their sexuality is just one part of them.

\section{Superordinate theme 2: Barriers to intervention}

This theme considers factors that pose as barriers to SU when accessing intervention, including the issues of anonymity and confidentiality.

\section{Subordinate theme 2.1: SU's lack of trust in services}

Within the narratives participants showed perception of SU mistrust and fear in terms of being reported if they were to contact services for help with sexual deviancy:

There's a lot of fear for people in accessing help on a face to face basis if the person hasn't been arrested...if they haven't got a conviction erm that can make them worry about getting help because of course our confidentiality is limited in the sense that if we get calls from people and they identify themselves or any children that are at risk of course we have to pass that information on. (Participant 5)

Somebody I was speaking to a minute ago who has been arrested for accessing indecent images tried to stop previously and found our website and the stuff on there but was, had thoughts and beliefs that the website was linked to the police ...he was very honest and sort of said nothing anybody could have told me at that time would have convinced me that actually yes that was anonymous and confidential. (Participant 1) 
They perceive that somehow that their information is going to be automatically passed onto the police, then of course they're gonner be wary about making contact... we know that when some people call us that they're very worried you know, quite seriously paranoid sometimes, about what's going on and is this phone call being recorded etcetera etcetera etcetera so there's a trust issue. (Participant 3)

These extracts highlight the challenge of prevention work in encouraging individuals with concerns about their sexual thoughts, feelings or behaviours around children to access help. Fear of being detected while searching for appropriate services, or even being reported once in contact with them, becomes a barrier between SU's and getting help until thoughts are inflated to riskier or even offending behaviour. Primary prevention efforts ideally hope to engage individuals prior to this; therefore SU's lack of trust in services that provide intervention becomes a barrier to primary prevention. SU fears over being reported or detected may at least be partially addressed by wider publication of confidentiality policies, and media campaigns that are empathic, non-judgemental or discriminatory, and assure anonymity (Beier et al., 2015).

\section{Subordinate theme 2.2: Anonymity- undetected SU's}

The issue of anonymity was apparent to participants as a barrier to intervention, specifically for those SU's who had committed offences but were undetected by the authorities:

\footnotetext{
Because it's anonymous if they haven't been arrested then that can be quite hard to manage sometimes, because you know someone's done it but they haven't been caught ...I guess our advice is that you could hand yourself in because you have done a bad thing, and you won't be able to access the full sort of support that you could potentially get if you were arrested if you really want to stop...obviously a lot of them are reluctant to do that because they know the consequences. (Participant 2)
}

Obligations for practitioners to report any concerns about child safety or offending behaviour, past or present, considerably restrict the services accessible to those who disclose such information on an anonymous basis. Individuals cannot come forward and receive help for abusing behaviour without being reported therefore prevention must develop strategies to reach those with deviant sexual interest before they abuse (Henry, 2001). Although helpful in some ways by encouraging individuals to come forward, anonymity closes the door on face to face or group work, and limits treatment to phone conversations. This comes with difficulties, such as getting dialogue flowing and lack of visual cues for the practitioner. 
The reality is there's only so much you can do with somebody over the helpline if they're not in the criminal justice process, I mean we're trying to be more creative about that in terms of delivering sessions over the phone to people who can then still retain their anonymity but I think that's an issue that stops us [doing what] we really need to be working on. (Participant 4)

However participants advocate that SU's receiving support after contact with the CJS express difficulty in accessing services (early in their offending pathway) prior to arrest or investigation:

One of the things that people kind of complain about in relation to other services is erm is not being able to get access to services before they're convicted. (Participant 5)

In the current situation it seems arrest opens the door to intervention, which is why practitioners by their own assertion encourage and assist SU's in making disclosures to the police. This is an issue for those who have done the 'right thing' (Participant 3) and sought help before offending but wish to remain anonymous.

\section{Superordinate theme 3: Prevention: missing pieces}

This theme discusses ways in which participants feel prevention could be improved from their perspective.

\section{Subordinate theme 3.1: Publicity and funding}

This theme considers how publicity and funding interact, and how improvements in these areas could improve the utility of prevention efforts.

A lot of the men that have been arrested said that they'd never even heard of us and they tried to access help and they couldn't find anyone like us. (Participant 2)

We tend to get 'I wish I knew about this organisation before [my arrest] you know you should advertise more!' (Participant 1)

These anecdotes highlight recognition that services are less accessible prior to involvement with the CJS. From a public health perspective (McMahon, 2000) this needs to be addressed; importantly participant narratives express lack of funding as a relevant consideration:

I think... not having a huge amount of funding and things like that, we cannot get ourselves out there as much as we would like to. (Participant 1) 
We can't always answer all the calls that come through so that can feel quite frustrating, when we know that there's people trying to get through to the helpline and they can't because we don't have enough funding to have more lines open, erm I guess the other sort of challenges erm the amount of funding we have available to provide face to face services, so sometimes people will be able to kind of make a contribution in other cases they won't and we will obviously wanna help as many people as we can but our resources aren't unlimited. (Participant 5)

Lack of investment poses a barrier to intervention in multiple ways. First, Organisation 1 currently receive limited funding, therefore SU's are often required to contribute or self-fund intervention resources, a significant obstacle for the unemployed or individuals from low income households (Horn, 2015). This brings difficult ethical considerations for practitioners, for example a SU working in a role with access to children may be encouraged by practitioners to step away from their job, to promote child safety. Yet in order to fully access resources the same individual would be required to self-fund or contribute financially to activities such as face to face intervention, which would prove problematic for many without income.

Second, limited resources result in limited publicity. Widespread or mainstream advertising has proved useful for international projects in engaging SU's prior to offending. For example, Beier et al., (2009) demonstrate the utility of media campaigning in reaching potential perpetrators of CSA. Posters were displayed on print media and city billboards, as well as a television advertisement broadcasted across multiple German channels (Beier et al., 2009). Pro bono support of the project from two large organisations allowed for the professional distribution of the campaign, which saw an influx of responses over the first 18 months. Of those who responded 58\% had no involvement with the CJS (Beier et al., 2009). Similarly, a Dutch based helpline service that utilise televised adverts report that $52 \%$ of their SU's make contact prior to offending (Horn, 2015). However, funding for this is not currently available to Organisation 1, therefore a large proportion of SU's (almost a third) are informed about the helpline by the police (Denis \& Whitehead, 2013). Recent figures show that only $28 \%$ of calls come from individuals who are concerned about their own thoughts or behaviours towards children- less than half of whom (42\%) have not yet offended (Dennis \& Whitehead, 2013).

Limited public awareness of the services ran by Organisation 1 can be tied back to the earlier discussion of confidentiality. Should the Organisation have increased means of advertising, specifically concerning details of their confidentiality policy, confidence in the service could 
be improved which may encourage anxious individuals with concerns about sexual deviancy to come forward.

Finally, any increase in publicity would hope to be reflected in the number of callers, particularly from those early in the offending pathway. Therefore increased service awareness would require more resources and investment to ensure that services can cope with an influx of callers following a campaign. It should be noted that the organisation is already stretched in terms of limited resources and the number of calls they receive:

Cos we've only got a limited amount of resources... if we did a huge drive on developing awareness about our services then, then we would need you know resources to deliver it. (Participant 5)

\section{Subordinate theme 3.2: Lack of adequate services}

In terms of missing pieces from a primary prevention perspective, practitioner narratives demonstrate an appreciation that Organisation 1 is a unique service and provides the 'first port of call' (Participant 1) for SU's seeking help. There is a current lack of other support or intervention for SU's from alternative services:

A lot of them say that they haven't had any help or they haven't found anywhere that can help them prior to calling us. (Participant 2)

Sometimes, there might be a few people that have gone to see their GP and the GP has then either, if they have known about us, advised them to come to us but I would say the majority of times we're the first port of call. (Participant 4)

Whilst private therapy is an option for some, for other individuals within the target group it is not financially viable, and with UK prevention in its 'embryonic stages' (Participant 4) there is an apparent lack of opportunities for help. This is recognised within the literature; compared to treatment of paedophiles involved in the CJS, treatment with non-offending individuals is considered underdeveloped (Cantor \& McPhail, 2016). In times of little available funding it may be that there are few current options for non-offending paedophiles because primary and secondary prevention interventions are difficult to evidence (Brown \& Saied-Tessier 2015) and are therefore second to tertiary programmes which can demonstrate effectiveness to some degree via recidivism statistics. 
In addition to this apparent lack of services, the theme also expresses an inadequacy of available services as participant narratives point to issues around limited competency of other professionals in dealing with this client group. Since the majority of Organisation 1 SU's found out about the service through the police (Denis \& Whitehead, 2013), those who are seeking help outside of the CJS seem to do so elsewhere. Seeking help ought to be a positive step for SU's however, participants express experiences of apprehensive SU's following negative responses from other organisations:
Someone quite specific comes to mind, who came to us because he'd been to his GP with his mental health problems and he'd been referred to a service and he disclosed that he had been looking at indecent images of children, erm and he was erm I'm trying to think of another word for rejected but he was told that they couldn't see him anymore because erm because he' $\mathrm{d}$ made that disclosure and he'd admitted looking at indecent images to the police which is how he found out about our service. (Participant 2)
Some people who have contacted the [Organisation 2] who have then been open about their behaviour have really not felt that they've had a very positive response from the [Organisation 2] and that's, I've spoken to my colleagues about that so you know and not being alright with an organisation and not being able to talk to them about this and feeling sort of judged really. (Participant 4)

This sort of ostracism (perceived or real) is a problem because rejection may threaten selfesteem (Leary \& Erlbaum, 2006) and self-worth, highlighted in the cycle of sexual offending behaviour (Wolf (1984; Cited in Silverman \& Wilson, 2002) as an initiator of patterned emotion and behaviour which eventually leads to sexual offending. Supporting this is robust evidence that sexual offenders experience low self-esteem (Marshall, Marshall, Serran \& O'Brien, 2009). In this case, negative experiences may reduce engagement or even direct individuals towards offending behaviour. In addition, research regarding mental health disorders such as schizophrenia reports that exclusion or discrimination when in contact with mental health professionals leads to feelings of stigmatisation (Schulze \& Angermeyer, 2003). The stigma around individuals with sexual interest in children is well documented (Jahnke \& Hoyer, 2013) thus, this may negatively impact primary prevention by adding to a stigmatic climate that discourages individuals from seeking therapeutic help (Imhoff, 2015).

Finally, there are problems for individuals who specifically are both previous victims and current or potential perpetrators of CSA, despite research that demonstrates a high percentage of male sex offenders possess this type of dual presentation (Glasser et al., 2001). Evidence 
suggests that victimisation as a child is a risk factor for perpetrating later abuse (Bentovim, 2002) and both aspects of this dual presentation require therapeutic support however, there is currently no specific organisation or co-ordinated services that can offer such help. Ideally voluntary sector organisations would engage with one another in order to work together in a more cohesive way when addressing the issue of CSA (Morgan \& Findlater, 2012).

\section{Subordinate theme 3.3: Education}

'Education' was repeatedly flagged by participants in relation to questions regarding what is missing from prevention efforts:

I think because the subject is so taboo not a lot of people talk about it, and actually I think some people might feel if everyone talks about it it normalises it a little bit but I think in order to prevent more people from doing it there does need to be a lot more education, and the men have said that to me themselves. (Participant 2)

I think there's also sort of educative stuff that we could be working on sort of more generally erm across the country in terms of primary education in schools and in public health and awareness raising. (Participant 4)

Participants were seemingly vague about what 'education' might look like, in some accounts education seemed synonymous with public awareness of services (publicity) which although is an issue (see above) would not require a specific education programme as such. Public perception of paedophilia is a potential area for improved education; despite some research describing public knowledge as adequate (McCartan, 2004) improvements could be made (McCartan, 2008). For example, evidence suggests that punitive attitudes of paedophiles are considered socially desirable (Imhoff, 2014), greater public education of paedophilia may be useful in reducing stigmatisation (Janhke \& Hoyer, 2013).

Finally in terms of education received by SU's, given that research estimates a time frame of almost a decade between onset of sexual fantasies and the time of the first arrest (Piche et al., 2016) it is likely that a large proportion of SU's are older and therefore did not access schoolbased educative prevention as children, because programmes have been implemented in recent years (e.g. NSPCC schools service; ESPACE programme). The participants' expression of calls for education from SU's may now be irrelevant as there are education programmes in place. However, it is difficult to estimate how useful school-based intervention would be, since most are aimed at empowering children against CSA in an age appropriate way (Brown \& 
Saied-Tessier 2015), whereas resources that inform individuals about how to deal with sexual interest in children are essentially non-existent unless that individual has been involved in the CJS. Again there is the issue that educative prevention is difficult to evidence, that is it is difficult to demonstrate when a victim or perpetrator of CSA has been prevented due to involvement with a specific programme. This relates back to lack of funding, as policy makers tend to favour evidence-based practise when allocating funds.

\section{Conclusion}

The aim of this study was to improve understanding of individuals at risk of perpetrating CSA and their needs, by exploring the experiences of practitioners who work with such individuals on a daily basis via an anonymous helpline. Achievement of this aim is reflected in the following novel findings. First, participants reported recognition that the SU's primary reason for calling the helpline was an increase in 'concern' regarding an individual's sexual interest in children. Ensuring SU's capacity to engage and addressing risk factors such as isolation and support helps to move SU's forward with intervention. In contrast, SU's lack of trust in services and fears around being reported are considerable barriers to treatment for individuals who have not engaged in offending behaviour. Participants express a struggle for SU's in terms of accessing services before involvement with the CJS, which in some cases is related to a need for anonymity.

In terms of what is missing from prevention, participants suggest that adequate services are lacking in a number of ways, and those that are available require wider publicity to encourage individuals to come forward. This is hindered by limited funding in both a practical sense of expenditure for media use, and the necessity of reinforcing services to cope with increased SU's following any increase in public awareness. These findings show that future prevention should increase effort in engaging potential abusers by publically advertising services in a way that encourages SU's to trust professionals, while continuing to work with those who do reach out for help by addressing risk factors and helping individuals immerse themselves in intervention.

The importance of a public health approach to CSA prevention is emphasised in the introduction and rationale for this study. It is important to note that this is the first study to consider the perspectives of those who manage individuals with sexual interest in children and 
therefore have insight into their needs. However, the following limitations should be noted. First, findings are based on practitioners self-reported views and perspectives which carries the potential limitation of respondent bias due to social desirability (Rubin, 2000), particularly as participants are staff members. However, participants appeared open in their responses and the consistency of responses across participants is encouraging. Additionally, due to the qualitative methodology utilised and a somewhat limited number of available participants, this study presents a relatively small sample size which limits generalisability to wider populations. However, the sample size is considered to be appropriate for the research project undertaken and the chosen analyses (Braun \& Clarke, 2013). Despite these limitations the findings are still considered to inform knowledge surrounding the needs of those who may be at risk of engaging in CSA in order to establish how it might be prevented.

To further the development of research in this field, more research on non-offending SU's is required to fully explore the way in which they are supported by the helpline, although it is recognised that this group may be reluctant to engage in research. Alternatively, future research may wish to include other important perspectives to gather a well-rounded view on the needs of individuals who are sexually attracted to children, for example retrospective views surrounding prevention from convicted sexual offenders in the UK.

The present research may be used to inform a wider prevention project to piece together strategies for engaging potential abusers with intervention, and establishing a way forward in tackling CSA. In terms of informing future prevention strategies, the presented findings encourage future approaches to recognise the importance of identifying and addressing risk factors for individuals who manage to reach out to services, in order to move forward with intervention. Additionally, clear communication of reporting laws to potential abusers to increase trust in services may prove beneficial in improving engagement with services, as individuals need to be encouraged to come forward and get help before thoughts or feelings manifest as abusive behaviours. Finally, findings demonstrate that more needs to be done in terms of securing funding for primary prevention strategies in order to prevent future victims. Much of the current research suggests that media campaigns not only assist with increasing the use of prevention services, but also help to inform the public about the issue which may help in addressing society's lack of support for solutions to CSA (Henry, 2001).

\section{References}


Beier, K. M., Grundmann, D., Kuhle, L. F., Scherner, G., Konrad, A., \& Amelung, T. (2015). The German Dunkelfeld Project: A pilot study to prevent child sexual abuse and the use of child abusive images. The journal of sexual medicine, 12, 529-542.

Beier, K. M., Neutze, J., Mundt, I. A., Ahlers, C. J., Goecker, D., Konrad, A., \& Schaefer, G. A. (2009). Encouraging self-identified pedophiles and hebephiles to seek professional help: First results of the Prevention Project Dunkelfeld (PPD). Child Abuse \& Neglect, 33, 545-549.

Bentovim, A. (2002). Preventing sexually abused young people from becoming abusers, and treating the victimization experiences of young people who offend sexually. Child abuse \& neglect, 26, 661-678.

Blagden, N., Winder, B., Gregson, M., \& Thorne, K. (2013). Working with denial in convicted sexual offenders a qualitative analysis of treatment professionals' views and experiences and their implications for practice. International journal of offender therapy and comparative criminology, 57, 332-356.

Bonnar-Kidd, K. K. (2010). Sexual offender laws and prevention of sexual violence or recidivism. American Journal of Public Health, 100, 412-419.

British Psychological Society (2006) Code of Ethics and Conduct. Leicester: British Psychological Society

Braun, V., \& Clarke, V. (2006). Using thematic analysis in psychology. Qualitative Research in Psychology, 3, 77-101

Brown, J., \& Saied-Tessier, A. (2015). Preventing Child Sexual Abuse Towards a national strategy for England. London: NSPCC

Cantor, J. M., \& McPhail, I. V. (2016). Non-offending Pedophiles. Current Sexual Health Reports, 1-8.

Code of ethics and conduct (2009). Guidance published by the Ethics Committee of the British Psychological Society. British Psychological Society

Council of Europe Strategy for the Rights of the Child (2012-2015): Implementation report

Denis \& Whitehead (2013). Stop it Now! UK \& Ireland Helpline and Campaign Report 20022012.

Duwe, G. (2013). Can Circles of Support and Accountability (COSA) work in the United States? Preliminary results from a randomized experiment in Minnesota. Sexual Abuse: $A$ Journal of Research and Treatment, 25, 143-165.

Feelgood, S., Ahlers, C. J., Schaefer, G. A., Ferrier, A., \& Beier, K. M. (2002). Generation of concrete ideas for a media campaign to motivate undetected sexual offenders to seek 
treatment using the Marketing Psychology approach. International Conference of the International Association for the Treatment of Sexual Offenders (IATSO), 11, 14.

Gibson, L. and Leitenberg, H. (2000) Child sexual abuse prevention programs: do they decrease the occurrence of child sexual abuse? Child Abuse and Neglect, 9, 1115-1125.

Glasser, M., Kolvin, I., Campbell, D., Glasser, A., Leitch, I., \& Farrelly, S. (2001). Cycle of child sexual abuse: Links between being a victim and becoming a perpetrator. The British Journal of Psychiatry, 179, 482-494.

Hanson, R. K. (2002). Recidivism and age: Follow-up data from 4,673 sexual offenders. Journal of interpersonal violence, 17, 1046-1062.

Hanson, R. K., Steffy, R. A., \& Gauthier, R. (1993). Long-term recidivism of child molesters. Journal of consulting and clinical psychology, 61, 646.

Henry, F. (2001). 'A prescription for change on child sexual abuse', Presentation to national advisory council on violence and abuse. American Medical Association.

Horn, J. V., Eisenberg, M., Nicholls, C. M., Mulder, J., Webster, S., Paskell, C., \& Jago, N. (2015). Stop It Now! A pilot study into the limits and benefits of a free helpline preventing child sexual abuse. Journal of child sexual abuse, 24, 853-872.

Imhoff, R. (2015). Punitive attitudes against pedophiles or persons with sexual interest in children: does the label matter?. Archives of sexual behavior, 44, 35-44.

Internet Watch Foundation (2015). Annual report. Retrieved from: www.iwf.org.uk

Jahnke, S., \& Hoyer, J. (2013). Stigmatization of people with pedophilia: A blind spot in stigma research. International Journal of Sexual Health, 25, 169-184.

Jütte, S., Bentley, H., Miller, P., \& Jetha, N. (2014). How safe are our children?. London: NSPCC.

Leary,.R. \& Erlbaum L.(2006). Interpersonal Rejection as a Determinant of Anger and Aggression Personality and Social Psychology Review, 10, 111-132.

Levenson, J. S., \& Cotter, L. P. (2005). The effect of Megan's Law on sex offender reintegration. Journal of Contemporary Criminal Justice, 21, 49-66.

Levenson, J. S., \& Macgowan, M. J. (2004). Engagement, denial, and treatment progress among sex offenders in group therapy. Sexual Abuse: A Journal of Research and Treatment, 16, 49-63.

Maltz, W., \& Maltz, L. (2009). The porn trap: The essential guide to overcoming problems caused by pornography. Harper Collins. 
Marshall, W. L., Marshall, L. E, Serran, G A.,\& O'Brien, M.D., (2009), Self-esteem, shame, cognitive distortions and empathy in sexual offenders: their integration and treatment implications. Psychology, Crime \& Law, 15, 217-234.

McCartan, K. F. (2004). "Here there be monsters"; The public's perception of paedophiles with particular reference to Belfast and Leicester. Medicine, Science and the Law, 44, 327-342.

McCartan, K. F. (2008). Current understandings of paedophilia and the resulting crisis in modern society. Psychological sexual dysfunctions, 51-84.

McMahon, P. M. (2000). The public health approach to sexual violence prevention. Sexual Abuse: A Journal of Research and Treatment, 12, 27-36.

Morgan, R. \& Findlater, D., (2012) Stop it Now! Wales, All Wales review on child sexual abuse prevention. Executive Summary.

National Crime Agency (2013). Crime and Courts Bill. Fact sheet 11 of 12 on the National Crime Agency: child protection. Home Office

NSPCC.org (2016a). Sexual Abuse what is sexual abuse? Retrieved From: https://www.nspcc.org.uk/preventing-abuse/child-abuse-and-neglect/child-sexual-abuse/

NSPCC.org (2016b). Child sex offender disclosure scheme. An information service factsheet. Retrieved from: https://www.nspcc.org.uk/services-and-resources/research-andresources/factsheet-and-briefings/child-sex-offender-disclosure-scheme/

Piché, L., Mathesius, J., Lussier, P., \& Schweighofer, A. (2016). Preventative services for sexual offenders. Sexual abuse: a journal of research and treatment.

Radford, L., Corral, S., Bradley, C., Fisher, H., Bassett, C., Howat, N., \& Collishaw, S. (2011). Child abuse and neglect in the UK today. London: NSPCC

Rubin, A. (2000). Standards for rigor in qualitative inquiry. Research on Social Work Practice, $10,173-178$.

Schulze, B., \& Angermeyer, M. C. (2003). Subjective experiences of stigma. A focus group study of schizophrenic patients, their relatives and mental health professionals. Social science \& medicine, 56(2), 299-312.

Seto, M. C. (2008). Pedophilia and sexual offending against children: Theory, assessment, and intervention. American Psychological Association.

Silverman, J., and Wilson, D. (2002). Innocence Betrayed: Paedophilia, the media \& society. Cambridge: Polity

Smallbone, S., Marshall, W., \& Wortley, R. (2008). Preventing Child Sexual Abuse: Evidence, policy and practice. Routledge 
Tewksbury, R., \& Mustaine, E. E. (2006). Where to find sex offenders: An examination of residential locations and neighborhood conditions. Criminal Justice Studies, 19, 61-75.

Thornton, D., Beech, A., \& Marshall, W. L. (2004). Pretreatment self-esteem and posttreatment sexual recidivism. International Journal of Offender Therapy and Comparative Criminology, 48, 587-599.

Whitaker, D. J., Lutzker, J. R., \& Shelley, G. A. (2005). Child maltreatment prevention priorities at the centers for disease control and prevention. Child Maltreatment, 10, 245259.

Willig, C. (2008). Introducing qualitative research methods in psychology. Maidenhead, England: McGraw Hill.

Wilson, R. J., Cortoni, F., \& McWhinnie, A. J. (2009). Circles of Support \& Accountability: A Canadian national replication of outcome findings. Sexual Abuse: A Journal of Research and Treatment, 21, 412-43 